years. In this series there were 82 men and 294 women; the percentage of those following a profession was higher in the case of the men, who as a group also showed a higher incidence of professionally employed, when compared to a group of patients treated for other conditions. Yet when all migrainous patients are studied as one group, a greater incidence of the affection amongst professional people is not found: in fact the reverse is the case. "This study would seem to indicate that one does not have to be a 'brain worker' to be a fit subject for migraine." The seemingly greater frequency of migraine among professional men is due to the fact that the nature of their work compels them to seek relief from this condition.

ARnOld Sorsby.

\title{
OBITUARY
}

\section{Mr. F. RICHARDSON CROSS, M.B., F.R.C.S., LL.D.}

IT is a trite saying " that manners make the man," but it was well exemplified in the late $\mathrm{Mr}$. Richardson Cross who died after an exceedingly full and busy life on July 12 last, in his 84th year, following an attack of influenza. Possessed of striking and handsome features, a tall well-knit athletic figure, his open and charming manners secured for him a host of friends and admirers in various walks of life: in his consulting room, in the hospitals with which he was connected, at the University, at scientific societies, in the Civic chamber, on the Bench, and in the hunting field.

The son of the Rev. Joseph Cross, he was born at Meriott Vicarage, Somerset, and educated at Crewkerne Grammar School and King's College Hospital, London, where he served as House Surgeon and came under the influence of Sir William Fergusson. Qualifying as M.R.C.S. in 1871, he held at King's College the posts of Medical Tutor, Sub-Dean, and Assistant Demonstrator of Anatomy. He served also as a Clinical Assistant at the Royal London Ophthalmic Hospital in the days of Bowman and Critchett. He became F.R.C.S. in 1878 and shortly after M.B. of the London University. In 1878 he left London in order to take a teaching post in anatomy at the Bristol Medical School, and continued to reside at Bristol for the remainder of his life. He joined the staff of the Bristol Royal Infirmary first as a General Surgeon, and practised as such in association with ophthalmology for six years. He was one of the first to introduce Listerian 


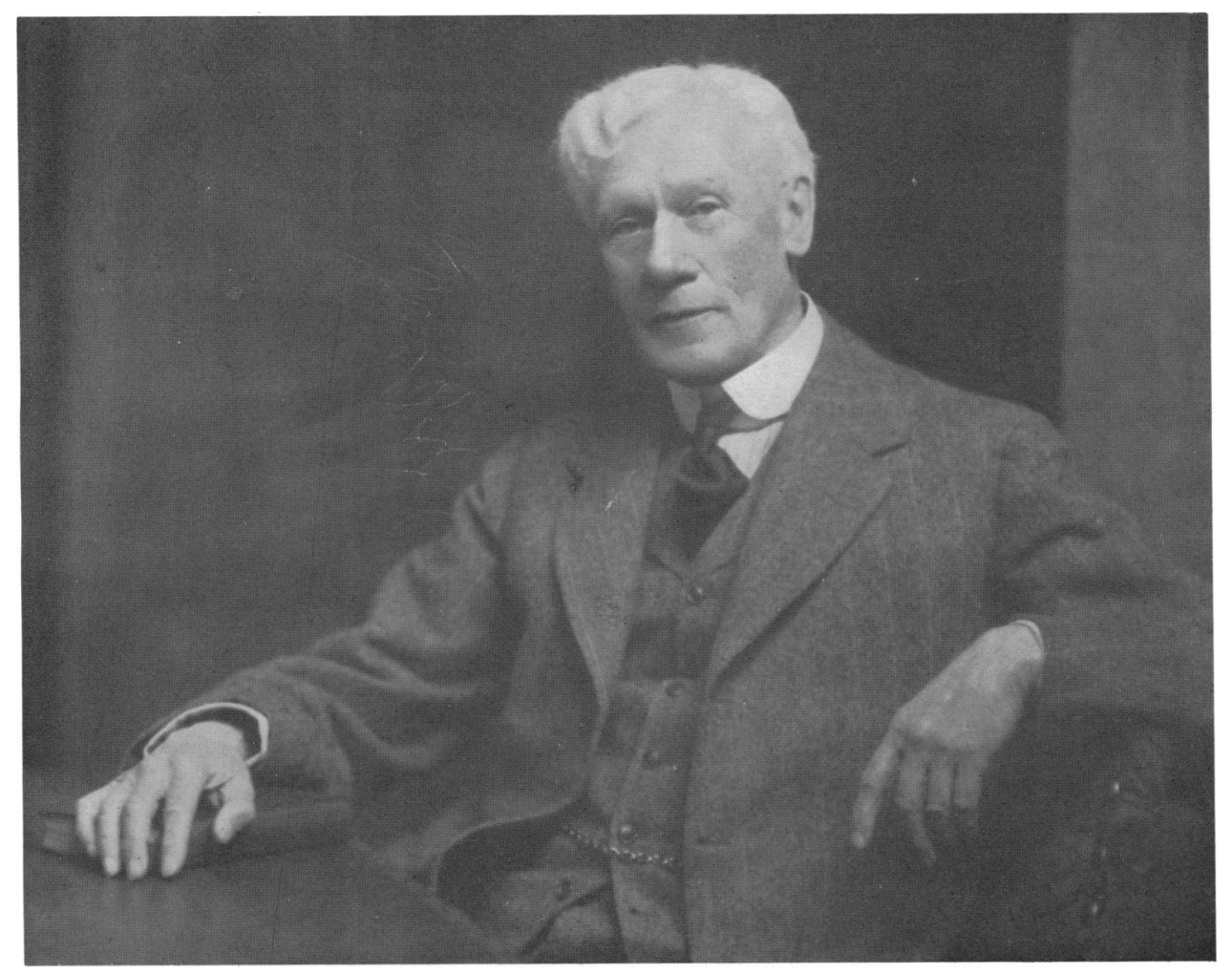

F. RICHARDSON CROSS, M.B., F.R.C.S., LL.D. 
methods into the West of England, Lister having joined the surgical staff at King's College Hospital on the death of Sir William Fergusson before Cross left London.

Like Critchett, and Bowman before him, Cross gradually found the demands of ophthalmic practice become so absorbing that he was obliged to restrict himself entirely to it. His first appointment as an Ophthalmic Surgeon was to the Eye Dispensary at Bristol. On giving up general surgery he became Ophthalmic Surgeon to the Royal Infirmary. In 1882 he joined the staff of the Bristol Eye Hospital, continued in active service there for a period of $\mathbf{4 4}$ years, and by his administrative ability raised it into a highly esteemed, up-to-date and efficient institution.

He became a Member of the Ophthalmological Society of the United Kingdom shortly after its formation in 1881, was a frequent attendant at its meetings and made many contributions to its proceedings. He was elected its President in 1914.

In 1885, Mules, of Manchester, introduced his operation of evisceration of the globe with the insertion of an artificial vitreous, and Cross, "who had been brought up in the school of " conservative surgery," at once commenced to perform it. Of a series of cases he described at the Society in 1887 there were two which had been followed by a mild form of sympathetic ophthalmitis. Later, he with naïve humour described a case, though it told somewhat against himself, in which he had inserted a silver globe and where argyrosis subsequently took place, causing so much discoloration that the condition was for a time mistaken for one of a recurrent melanotic growth in the orbit.

In 1890, Cross described the remarkable case of a young woman who shed blood-stained tears, and caused much amusement to members of the Society by handing round a handkerchief she had used with blood-stained spots on it, as a proof of the genuineness of his observation.

He contributed two papers on "Hydrophthalmos "; in the first, dealing mainly with the literature of the subject and attempting to differentiate between the terms, "hydrophthalmos," "buphthalmos," and " megalophthalmos "; in the second, he described two congenital cases where he had examined the eyes pathologically, and which he said strongly supported the view that the essential cause of the affection lies in the imperfect condition of the filtration area.

In 1892 , he recorded a case in which he had performed extraction of cataract, and which after six months of good vision had developed glaucoma so that the eye had to be removed. Its pathological examination showed that the surface corneal epithelium had extended through the wound and spread round the whole of the anterior chamber. 
In his Presidential Address in 1914 he gave a review of the Society's activities since its foundation, and among many sage remarks compared a specialist who had not had a fair knowledge of general medicine to " a bird with but one wing."

Being a fluent and attractive speaker Cross's services as such were frequently sought as a lecturer; on behalf of charitable institutions, and as a proposer of toasts at public dinners. His lectures may be best described as scenic representations drawn in bold outlines on a large canvas, rather than miniatures full of intensive detail such as specialists are often prone to produce. Thus his Oration at the Medical Society of London in 1901 dealt with " Some Landmarks in the Progress of Medical Science." His Bradshaw Lecture at the Royal College of Surgeons in 1909 was entitled "The Brain Structures concerned in Vision." His Long Fox Lecture at Bristol University in 1915 was on " The Evolution of the Sense of Sight." For the Doyne Memorial Lecture at Oxford, in 1920, he chose for his subject "The Nerve Paths and Centres concerned with Sight."

In 1898, he presented himself as a candidate for election to the Council of the Royal College of Surgeons, and it demonstrates well his popularity throughout the country that he was returned at the head of the poll, having received 411 votes with 74 plumpers. He continued to serve on the Council until 1914, the attendance at its meetings necessitating frequent journeys to London. Having attained remarkable reputation and success in practice in the West of England, like some other successful Extra-Metropolitan practitioners he had hankerings at times for practice in London. He did indeed for a while hold consultations in London in the rooms of a former assistant, though he never actually had his plate on the door. When reviewing his life towards its close, he admitted, however, that had he returned to London he could never have enjoyed the amenities of country life which he was able to participate in from his home in Bristol, and which he appreciated so fully.

Cross was a great lover of animals and a keen follower of the chase, hunting with the Berkeley. and the Duke of Beaufort's hounds, in connection with the latter becoming entitled to don the buff and blue. He owned a farm at Alverston in Gloucestershire where he found recreation in various forms of stock breeding, and possessed a pedigree herd of shorthorns.

In 1897, he was elected a Sheriff of the City of Bristol and a J.P.: to commemorate the birth of his third daughter during his year of office he was presented with a silver cradle.

In appreciation of his long services to the University of Bristol, first as a Dean of the Faculty, and later, as Lecturer and then Reader in Ophthalmology, he had conferred upon him the 
honorary degree of LL.D.; and in 1920 his portrait, subscribed for by his friends and admirers, was presented to the University.

Of the numerous other posts that he held and good works that he did during his long life a list only can be made here : Surgeon to the police force; Assistant Surgeon to the old Bristol Rifle Volunteers; Member of the Council of Clifton College; VicePresident of the Royal School for the Blind, Bristol; Chairman of the Bristol Centre of St. John's Ambulance; Governor of Queen Victoria's Jubilee Convalescent Home, Clifton; and President of the Grateful Society.

No man lives and dies to himself ; no one lives an isolated existence. We take from those who have preceded us, mostly from those with whom we are closely associated in our plastic early years, and we give to those who succeed us, mostly those who associate themselves with us in our prime. From Sir William Fergusson whom Sir James Paget described as "The greatest master of the art and the greatest practical surgeon of our time," Richardson Cross acquired not only his surgical ardour and manipulative dexterity, but also his social instincts and personal sympathies which won for him favour from all classes of mankind.

On joining the staff of the Bristol Royal Infirmary, Cross had as a colleague Dr. Edward Long Fox. In 1915, when Cross delivered the Long Fox Memorial Lecture he gave a description of his deceased friend's characteristics which correspond so closely to his own that it may be quoted here as a description of himself. Cross said :- " He was a student of science and a sound practitioner of medicine, ever extremely attentive to his cases, whether in hospital or in private, and he was a personal friend as well as adviser to his patients . . . . He was for several years the acknowledged head of the medical profession in Bristol, and possessed the full confidence of all his colleagues. Generous in his hospitality, and in his charitable support of hospitals and other deserving objects, his influence and effort were always available for any good work, and he helped in secret many poor and struggling individuals. He was always kind and helpful to young men starting in their profession . . . . at his death a very large circle lost a beloved personal friend, the profession of medicine one of its most trusted leaders, and the City of Bristol an honoured and valuable fellowcitizen."

At the Bristol Eye Hospital Cross had working with him a succession of house surgeons and assistants over whom he exerted a stimulating and inspiring influence, and on whom the impress of his personality became ingrained. Three of them predeceased him: Snellen Junior, who succeeded his distinguished father as Professor of Ophthalmology at Utrecht University; W. Ilbert Hancock, who became an Assistant Surgeon at Moorfields 
Hospital; and Alexander Ogilvie, who joined Cross on the staff at the Bristol Eye Hospital. Among his other house surgeons were Sir Richard Cruise, Bernard Cridland, of Wolverhampton, Thomson Henderson, of Nottingham, and E. R. Chambers, of Bristol.

Cross married in 1889 the daughter of Captain Hawkes, R.N., who died at the end of 1920 . He had three daughters who survive him.

$$
\text { E. T. C. }
$$

\section{NOTES}

French Course in Ophthalmic Surgery
PROFESSOR TERRIEN announces the annual French cours de perfectionnement to be held at the Hôtel Dieu in the month of October. The course begins on October 3, and will be composed of twelve lectures. $\mathrm{He}$ is assisted by Professor Regaud, M. Velter, and MM. Casteran, Veil, Renard, J. Blum, Dollfus and Mlle. Braun. A certificate will be given on completion of the course, and the fee has been fixed at 300 francs. Further information can be obtained from Professor. Terrien.

WE are asked by Dr. K. T. A. Halbertsma, of Heredity Delft, to call attention to the fact that the VIth International Congress of Genetics will be held in Ithaca (U.S.A.) from August 24 to 31, 1932. The German Society for the Study of Heredity meets from September 13 to 17, 1931, in Munich; and the XVth International Congress of Anthropology and Prehistoric Archaeology meets in Paris also in September, 1931. Dr. Halbertsma would like to meet those interested in the study of heredity and disease at either of these meetings.

\section{FUTURE ARRANGEMENTS}

\section{1}

October 6.-Midland Ophthalmological Society, at Birmingham. December 1.- Midland Ophthalmological Society, at Birmingham. 